\title{
EFFECT OF ESTROGENIC SUBSTANCE ON THE BLOOD SUGAR OF FEMALE DIABETICS AFTER THE MENOPAUSE ${ }^{1}$
}

\author{
By C. J. GESSLER, 2 J. A. HALSTED, ANd R. P. STETSON \\ (From the Thorndike Memorial Laboratory, Second and Fourth Medical Services (Harvard), \\ Boston City Hospital, and the Department of Medicine, Harvard Medical School, Boston)
}

(Received for publication August 2, 1939)

There is both experimental and clinical evidence that the anterior pituitary plays an important rôle in carbohydrate metabolism. Houssay (1) demonstrated that hypophysectomy alleviates the diabetic symptoms occurring after pancreatectomy. Young (2) has produced a permanent diabetic condition in dogs by injections of anterior pituitary extract. Syndromes due to hyperfunction of the pituitary, like acromegaly and Cushing's disease, often include hyperglycemia. In Simmonds' disease, in which there is decrease of pituitary function, hypoglycemia often occurs, as is the case with hypophysectomized animals. Such evidence indicates that when the pituitary is overactive there is likely to be hyperglycemia, and when it is underactive, hypoglycemia. This influence of the anterior pituitary has been attributed to a "diabetogenic factor"; and it is possible that increased pituitary activity in this respect plays a rôle in some cases of diabetes mellitus.

It is known that an antagonism exists between the stimulating hormones of the anterior pituitary and the hormones of the glands stimulated by the pituitary. This antagonism is demonstrable particularly in relation to the gonads. Thus it has been shown that gonadectomy results in an increased production of gonadotropic hormone by the anterior pituitary, while the injection of estrogenic substance prevents this overactivity or inhibits it once it has occurred. In humans the changes occurring at the menopause have been demonstrated by Albright (3) and others to consist of a decrease of ovarian estrogenic hormone and an increase of gonadotropic hormone. These changes can be rectified by injections of estrogenic substance. Moreover, it is probable that inhibi-

1 The expenses of this investigation were defrayed in part by a grant to Harvard University from the Smith, Kline \& French Laboratories, Philadelphia.

2 Graduate Fellow of the Belgian-American Educational Foundation, 1937 to 1939. tion of the pituitary activity by estrogenic substance extends to other pituitary hormones. Thus, in cases of climacteric thyrotoxicosis, Hoet and Gessler (4) were able to effect a reduction in the basal metabolic rate from around plus 50 to normal by injections of large amounts of estrogenic substance. It is probable that the thyrotoxicosis in these cases was due to increased production of thyrotropic hormone.

The effect of injections of estrogenic substance in diabetic conditions has been tested both experimentally and clinically. Barnes, Regan and Nelson (5) and Nelson and Overholser (6) improved the sugar tolerance and definitely prolonged life in depancreatized dogs (5) and monkeys (6) by estrin injections. Attempts also have been made to influence human diabetes. In 1928 Rathery and Rudolf (7) and Carnot, Terris and Caroli (8) claimed to have produced improvement in diabetic women by injections of estrin. The doses employed were so minute, however, (10 units) that it is unlikely that the changes which occurred were due to the influence of this small amount of estrogenic substance. Mazer, Meranze and Israel (9) have come to the conclusion that the blood sugar level of normal women remains unaffected by injections of large doses of estrogenic substance, but that the blood and urine of diabetic women who are subjected to similar treatment will show an appreciable decrease in the sugar content. These workers give little detailed information concerning their 3 patients except for the fact that the maximum fall observed in the fasting blood sugar values was $60 \mathrm{mgm}$. per $100 \mathrm{cc}$. Jones and MacGregor (10) injected 10 non-diabetic women past the menopause with large doses of estrin without any effect on the blood sugar. In 1936 Collens, SloBodkin, Rosenbliett and Boas (11) gave 7 diabetic patients injections of estrogenic substance and came to the conclusion that this procedure had 
absolutely no effect on human diabetes. They used daily doses varying between 100 and 400 rat units. Glen and Eaton (12) improved the condition of a severely diabetic woman, in whom the diabetes apparently started after an ovariectomy, by injections of estrogenic substance. In this case there was said to be an increased amount of diabetogenic hormone in the blood, as tested by the method of De Wesselow and Griffiths (13).

One possible explanation for the conflicting reports in the literature may be the present inability to discriminate between those diabetics in whom the pituitary may have played an etiological rôle and those with purely pancreatic diabetes. If estrogenic substance can exert an influence on diabetes, such an effect theoretically should be demonstrable more easily at a life period when the organism is lacking in ovarian estrogenic hormone. With this in mind, it was decided to study the effect of injected estrogenic substance on the blood sugar of diabetic women who had passed the menopause.

\section{METHODS}

Five female diabetic patients who had passed the menopause were chosen for study. Two of these women (Cases 1 and 2) gave an unequivocal history of the simultaneous onset of the menopause and diabetes. In Case 3 menopause symptoms preceded by two years the detection of diabetes at the time of a panhysterectomy. In Case 4 the correlation was difficult to ascertain, but it is probable that the diabetes began shortly before the menses became irregular, amenorrhea occurring four years yater. In Case 5 the menopause preceded the sudden onset of diabetes by seven years.

The general experimental plan was as follows: In each instance the patient was maintained throughout the entire period of observation on a diet containing 151 grams of carbohydrate, 74 grams of protein and 92 grams of fat, with a caloric value of 1,728 calories. This diet was tolerated well and in no instance was there any significant change in weight during the period of observation. During a first period the patients were treated with insulin in addition to the basal diet. During the next control period, varying from five to fourteen days, no insulin was given and the fasting blood sugar values rose. During an immediately subsequent experimental period, intramuscular injections of estradiolbenzoate (Progynon B) ${ }^{3}$ in amounts up to 50,000 international units $(10,000$ rat units) were administered daily or otherwise, as shown in Figures 1 to 5. Throughout the entire period of observation the fasting blood sugar values were determined at frequent intervals on venous blood (Folin method). For convenience the experimental results in each case are discussed separately.

In 2 patients an attempt was made to determine whether they belonged, according to the method of Himsworth (14), to insulin-sensitive or insulin-insensitive types, respectively. In 4 patients urine assays for follicle-stimulating pituitary hormone were made both before and after the period of injection of estradiolbenzoate. Finally, the influence of these injections on the basal metabolic rate was determined in two instances.

\section{RESULTS}

Case 1. This 50-year-old white woman was found to have diabetes at the time of the menopause, six months previous to admission to the hospital. The diabetic condition was controlled by 30 units of protamine insulin a day. The results of this observation are given in Figure 1. During the eleven-day control period without insulin the fasting blood sugar values rose. During the first three days of the subsequent experimental period daily injections of 10,000 international units ( 1 cc.) of estradiolbenzoate were given, without any effect on the fasting blood sugar. The daily dose was then increased to 20,000 international units $(2 \mathrm{cc}$.) and continued at this level for twelve days, again with no effect on the fasting blood sugar values. After an interval of four days, 50,000 international units of estradiolbenzoate (1 cc.) were injected daily for six days. The fasting blood sugar values then decreased from around $230 \mathrm{mgm}$. and reached the lowest value of $178 \mathrm{mgm}$. per $100 \mathrm{cc}$. six days after the last injection of estradiolbenzoate. The fasting blood sugar values then slowly rose.

Case 2. This 62-year-old white woman developed diabetes within three months after the menopause, fourteen years before admission to the hospital. The diabetic condition was controlled by 35 units of protamine insulin a day. The results of this observation are given in Figures $2 A$ and $2 B$. During the control period of thirteen days without insulin the fasting blood sugar values rose to $267 \mathrm{mgm}$. per $100 \mathrm{cc}$. During the following experimental period daily injections of 50,000 international units $(1 \mathrm{cc}$.) of estradiolbenzoate were given over a

$3 \mathrm{We}$ wish to extend our thanks to the Schering Corporation for a generous supply of Progynon B. 


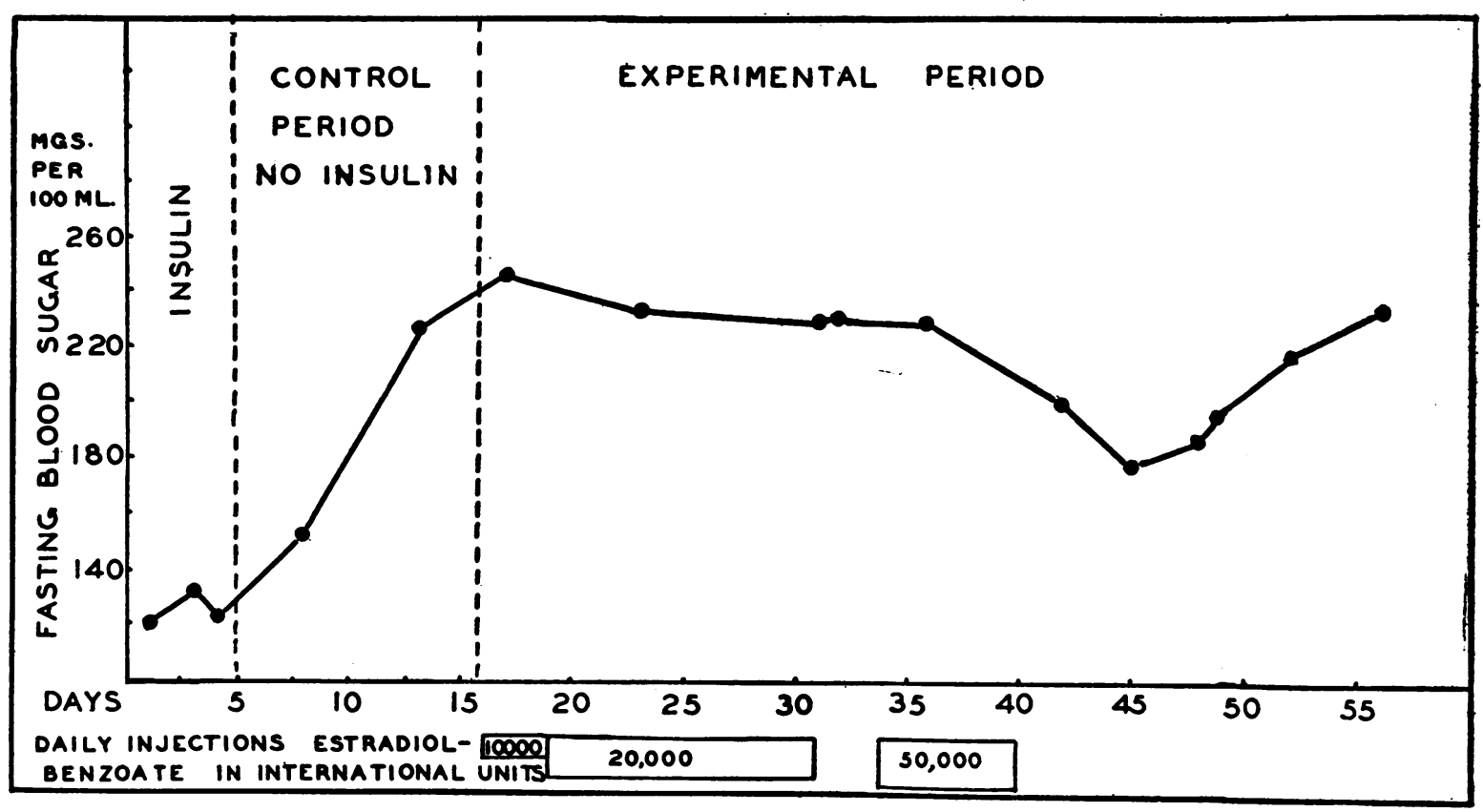

Fig. 1. Results of Estradiolbenzoate Injections in Patient Case 1

period of twenty-two days. The fasting blood sugar values fell to about $140 \mathrm{mgm}$. per $100 \mathrm{cc}$. after fourteen injections; further injections did not result in a significantly greater lowering. The fasting blood sugar remained around $140 \mathrm{mgm}$. per $100 \mathrm{cc}$. for nine days after the last injection of estradiolbenzoate, then started to rise and reached a level of $244 \mathrm{mgm}$. per $100 \mathrm{cc}$. on the sixty-sixth day.

The general condition of this patient was remarkably improved. She had suffered considerable pain from hypertrophic arthritis of both knees for one year. When first seen, she walked with difficulty. After the first four injections of estradiolbenzoate she volunteered the information that her arthritis had improved to such an extent that she could walk much better and could freely bend her right knee, which was previously stiff. Similar effects have been reported by Hall (15) in menopause arthralgia.

On the fifty-fifth day, while the fasting blood sugar was going up, the patient was discharged. Owing to her intelligence and cooperation it was possible to maintain the same diet at home and to continue the investigation. The results of the further observations are given in Figure $2 B$. On the sixty-sixth day 100,000 international units of estradiolbenzoate $(2 \mathrm{cc}$.) were injected. This was followed the next day by metrorrhagia of three days' duration. On the seventy-third day the patient received an injection of 50,000 international units of estradiolbenzoate ( $1 \mathrm{cc}$.) and from then on this amount was given twice a week. The fasting blood sugar again fell, but more slowly than during the period of daily injections. From an initial level of around 240 it reached a value of $171 \mathrm{mgm}$. per $100 \mathrm{cc}$. on the ninety- fourth day, after seven injections. The patient then burned her hand and missed the next injection; one or both of these factors may have been responsible for the subsequent peak in the fasting blood sugar values (242 mgm. on the one hundred and first day). After the resumption of injections of 50,000 international units of estradiolbenzoate twice a week, the fasting blood sugar values again decreased and reached $155 \mathrm{mgm}$. per 100 cc. on the one hundred and twenty-second day, after fifteen injections. On the one hundred and fifty-first day metrorrhagia set in and persisted in varying intensity for two weeks. The last injection of estradiolbenzoate was given on the one hundred and fifty-third day. The fasting blood sugar values then rose progressively and reached $263 \mathrm{mgm}$. per $100 \mathrm{cc}$. twenty-five days after the last injection.

Case 3. This 40-year-old white woman began to experience menstrual irregularities four years before entry to the hospital. Two years later a panhysterectomy was performed disclosing, according to a pathologist's report, late proliferating endometrium, early squamous cell carcinoma of the cervix, and thecal lutein cysts of the ovaries. On the day before operation she was found to have diabetes, which required 10 units of insulin and 15 units of protamine insulin daily for regulation when the patient entered the hospital for the present observations. As shown in Figure 3, during a control period of five days without insulin the fasting blood sugar averaged about $300 \mathrm{mgm}$. per $100 \mathrm{cc}$. Thereafter during the experimental period the patient was given fourteen daily injections of 50,000 international units of estradiolbenzoate each. After five days the fasting blood sugar level averaged about $240 \mathrm{mgm}$. per $100 \mathrm{cc}$. for nine days. Then, 


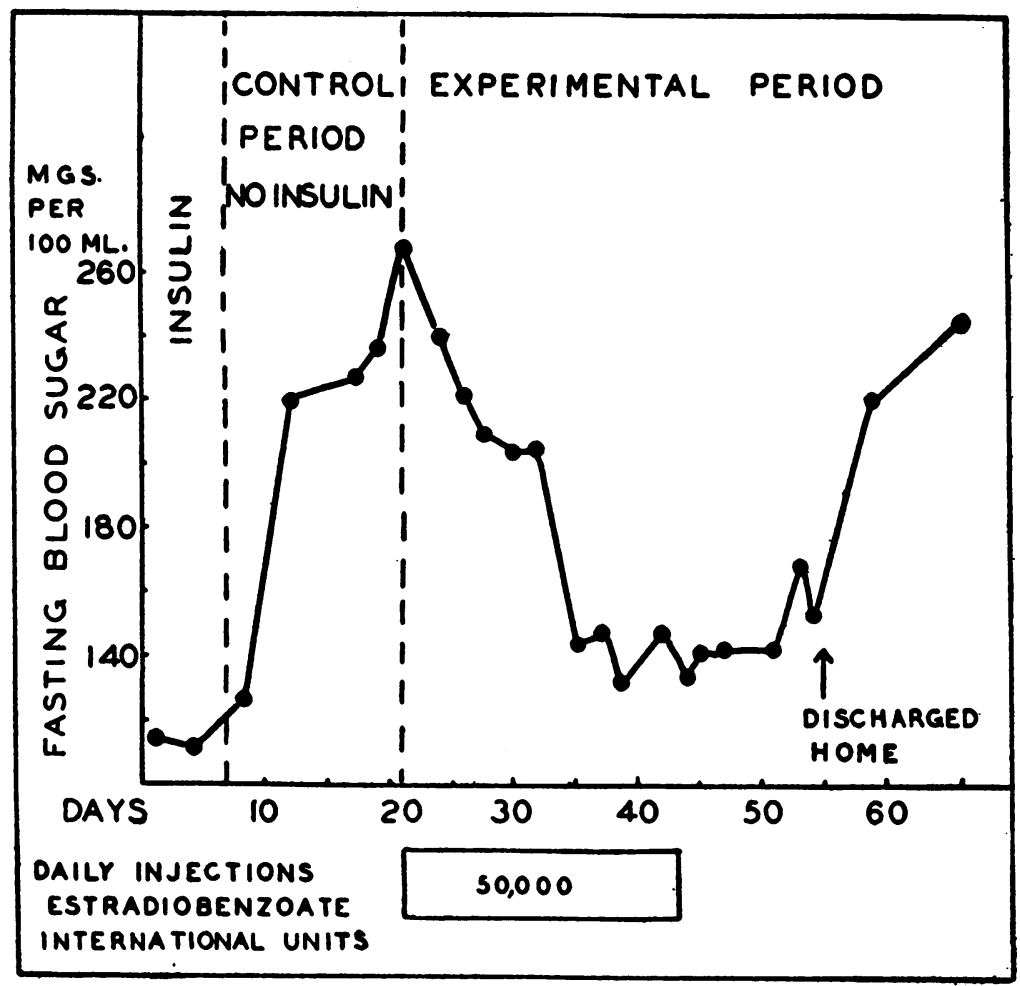

Fig. 2A. Results of Estradiolbenzonte Injections in Patient Case 2

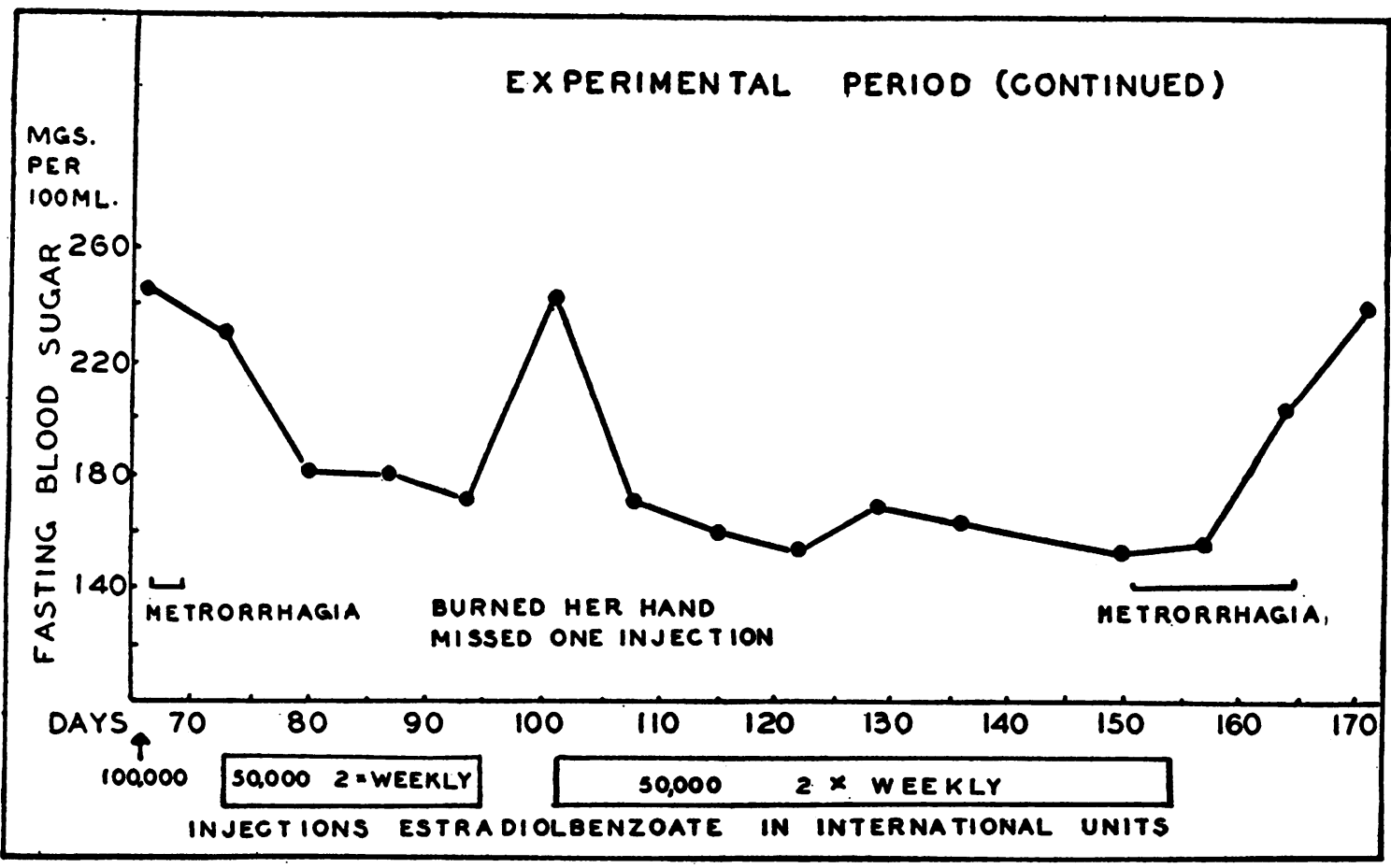

Fig. 2B. Results of Estradiolbenzoate Injections in Patient Case 2, Continued 


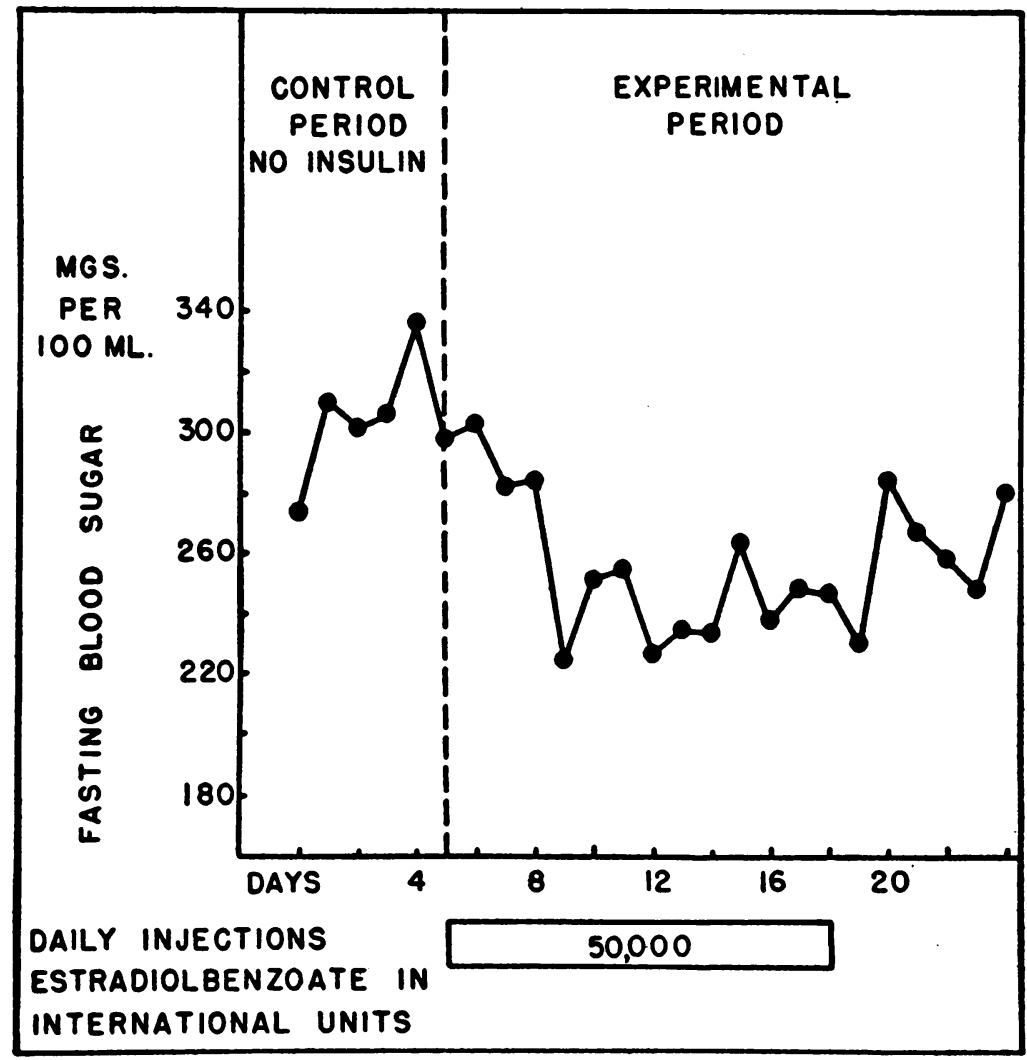

Fig. 3. Results of Estradiolbenzonte Injections in Patient Case 3

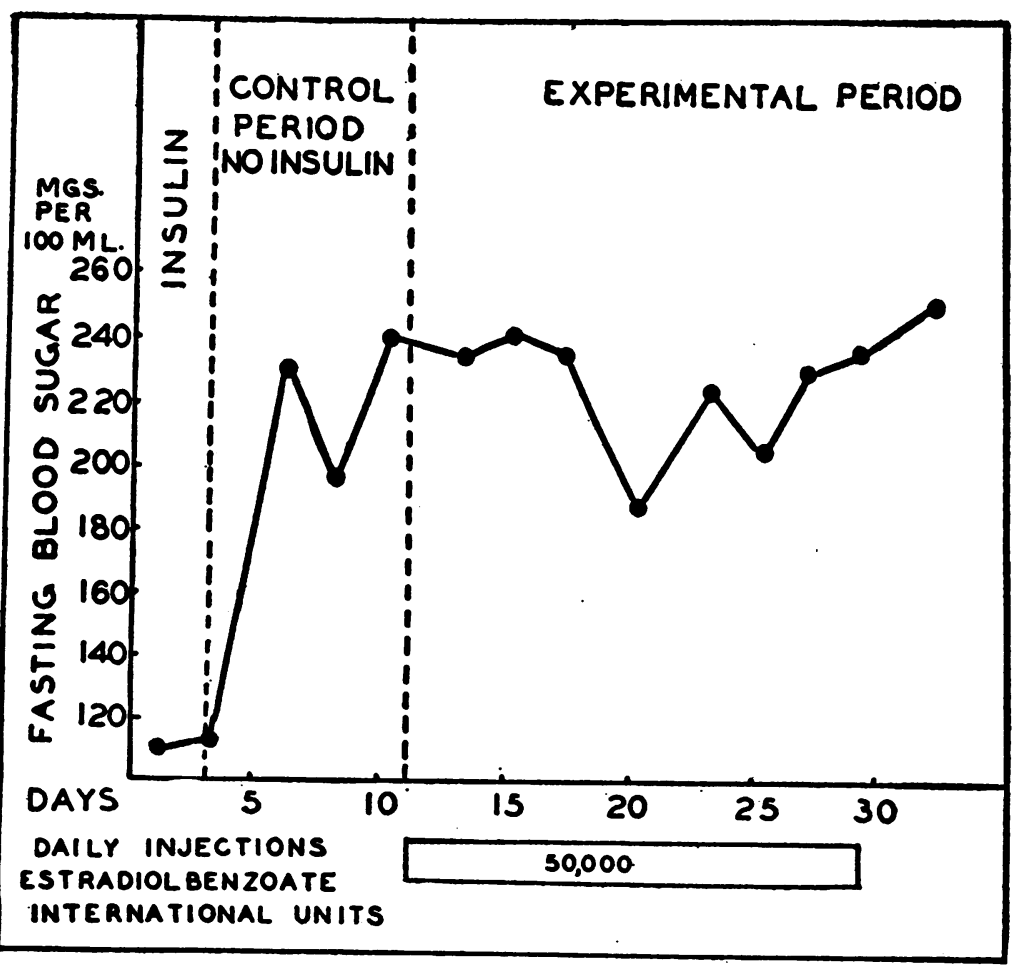

Fig. 4. Results of Estradiolbenzonte Injections in Patient Case 4 


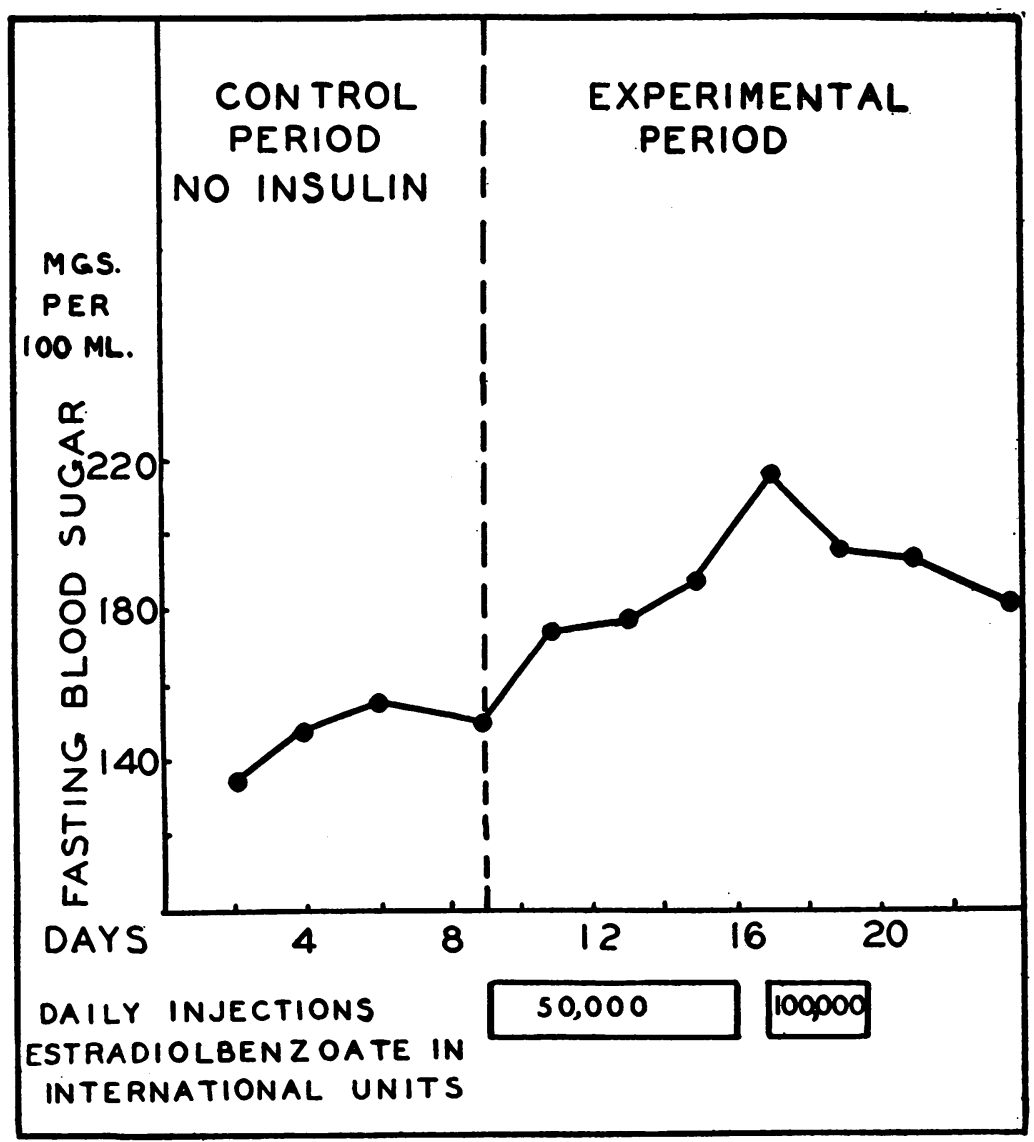

Fig. 5. Results of Estradiolbenzoate Injections in Patient Case 5

when the injections were discontinued, the data suggest that the fasting blood sugar was a little higher than during the injection period.

Case 4. This 54-year-old white woman apparently became diabetic eight years before entry to the hospital and shortly before the menses became irregular. Amenorrhea occurred four years later. The diabetic condition was controlled by 30 units of protamine insulin a day. The results of this observation are given in Figure 4. During the seven-day control period without insulin the fasting blood sugar values rose and finally reached 240 mgm. per $100 \mathrm{cc}$. During the following experimental period daily injections of 50,000 international units of estradiolbenzoate $(1 \mathrm{cc}$.) were given over a period of eighteen days. Despite considerable fluctuations during both the control and the experimental periods, the injected estradiolbenzoate had no consistent effect on the fasting blood sugar, which was $239 \mathrm{mgm}$. per $100 \mathrm{cc}$. on the thirty-second day after eighteen injections.

Case 5. This 58-year-old white woman experienced the menopause more than ten years before entry to the hospital. Seven years later she rather suddenly developed symptoms which led to the diagnosis of diabetes. This was controlled during the last two years with 25 units of insulin daily. The results of the observations are given in Figure 5. During a nine-day control period without insulin her fasting blood sugar averaged about $150 \mathrm{mgm}$. per $100 \mathrm{cc}$. During the subsequent experimental period daily injections of 50,000 international units for eight days and of 100,000 international units of estradiolbenzoate for three additional days did not prevent further increases in the fasting blood sugar level, which reached a maximum of $217.7 \mathrm{mgm}$. per $100 \mathrm{cc}$. on the ninth day of the experimental period.

Glucose tolerance. Glucose tolerance tests in our patients gave typical diabetic curves. Fifty grams of glucose were given orally instead of breakfast; samples of venous blood were taken every half hour for two or three hours, the patient remaining in bed during the test. An attempt was made in two of our cases to differentiate them according to Himsworth (14) into insulin-sensitive and insulin-insensitive types, using the glucose tolerance test with and without simultaneous intravenous injection of insulin. Case 2 apparently belonged to the insulin-insensi- 
tive group, while case 4 was of the insulin-sensitive type.

Urine assays for follicle-stimulating hormone. Tests for follicle-stimulating hormone were performed on twenty-four-hour urine specimens from Cases 1, 2, 4 and 5 both before and after injections of estradiolbenzoate. The method used was Zondek's alcohol precipitation test, using rats as the test animal.* With the particular technique employed, negative tests (less than 20 rat units per liter) are uniformly obtained in normal women before the menopause, and positive tests (at least 40 rat units per liter) are obtained in most cases after the menopause. In each of our 4 patients a positive test was obtained before the injections of estradiolbenzoate and a negative test was obtained two days after the last injection. These results indicate that the injections of estradiolbenzoate were effective in inhibiting the follicle-stimulating function of the anterior pituitary.

Influence of the injection of estradiolbenzoate on the basal metabolism. In Cases 2 and 4 the basal metabolic rate was measured before and after injection of estradiolbenzoate. In each instance the initial basal metabolic rate was normal or slightly low. In no instance did a significant change occur after the injections.

\section{DISCUSSION}

Urine assays in 4 of 5 diabetic women who had passed the menopause and who were given injections of 50,000 international units of estradiolbenzoate for several days indicated the effectiveness of this material in inhibiting the folliclestimulating function of the anterior pituitary. In 2 patients, Cases 1 and 2, in whom the diabetes began at the time of the menopause, the elevated fasting blood sugar values which were reached after the discontinuance of insulin therapy were significantly lowered by daily injections of 50,000 international units of estradiolbenzoate. Moreover, a few days after the last injection the fasting blood sugar values went up again. In the patient, Case 3, in whom diabetes appeared two years after the menopause began and at the time of surgical removal of the ovaries, it is probable

- The tests were performed by Miss Estelle Donovan and Miss Priscilla Spalding of the Aschheim-Zondek Laboratory of the Mallory Institute for Pathology of the Boston City Hospital. that a similar effect was obtained. The insistence of the patient on leaving the hospital, however, unfortunately prevented a sufficiently long period after the termination of the injections in which to observe a potential rise of the blood sugar. In the patient, Case 4, in whom the diabetes was discovered shortly before the menopause, no significant effect on the blood sugar was observed. In the patient, Case 5, in whom the menopause preceded the onset of the diabetes by at least seven years, there was no lowering of the blood sugar as a result of injections of estradiolbenzoate.

The blood sugar lowering effect is considered to have been due to inhibition of the diabetogenic factor of the anterior pituitary by the injected estradiolbenzoate. It is not necessarily an argument against this assumption that, although before the injection of estradiolbenzoate 4 of these 5 patients showed increased excretion of follicle-stimulating hormone, the blood sugar of only 3 responded significantly to estradiolbenzoate. Although estradiolbenzoate has been shown to be capable of lowering the elevated basal metabolic rate of women who have become thyrotoxic after the menopause (4), in the present observations the normal basal metabolic rate remained unaffected. Apparently the inhibitory effect of estradiolbenzoate is manifest only in the presence of excessive secretion of thyrotropic hormone of pituitary origin. Similarly, in the present observations the inhibitory effect of estradiolbenzoate in 3 of the patients may perhaps be taken to indicate an excessive influence of pituitary diabetogenic factor.

In future it may be possible, by means of tests for diabetogenic factor in the blood or urine (13) (16), to distinguish between two types of diabetes, one mainly pancreatic, the other mainly pituitary in origin. According to Himsworth's (14) technique, Case 2 belonged to the insulin-insensitive group, while Case 4 was apparently of the insulinsensitive type. The conflicting results in the literature on the subject of the effectiveness of estradiolbenzoate in diabetes may be due either to such differences in the type of diabetics studied or to the fact that insufficient amounts of estrogenic substance have been used. The negative results obtained by Collens and his associates (11) can certainly be explained on this basis, because they injected only 2,000 international units daily, whereas the observations on Case 1 indicate that 
daily injections of even 10,000 and 20,000 international units, respectively, were ineffective in lowering the blood sugar.

The type of patient most likely to respond to estradiolbenzoate would theoretically be the case in which the diabetes appeared with or shortly after the menopause, or shortly after the surgical removal of the ovaries. The activity of estradiolbenzoate in such patients would be expected to be most readily observed during or soon after the menopause. It is not the purpose of this article to discuss the nature of the diabetogenic factor in the anterior pituitary. Data on this subject can be found in the papers by Young (17) (18), Long (19), Houssay (1), Elmer, Giedosz and Scheps (20), Neufeld and Collip (21) and Taubenhaus (22).

\section{SUMMARY}

Five diabetic women who had passed the menopause were given intramuscular injections of estradiolbenzoate $(50,000$ international units daily). In the four instances tested, the excretion of follicle-stimulating hormone of the pituitary was significantly decreased by this procedure. A significant lowering of the fasting blood sugar resulted in 2 of the patients (Cases 1 and 2) in whom the onset of diabetes coincided with the menopause, and probably in a third (Case 3 ) in whom the menopause preceded the diabetes. It is suggested that this effect was due to inhibition by the injected estradiolbenzoate of a postmenopausal excessive production of the pituitary diabetogenic factor. In the other 2 patients (Cases 4 and 5), there was clearly no effect from the estradiolbenzoate injections. In Case 4 the onset of diabetes preceded the menopause and in Case 5 the menopause preceded the onset of diabetes by at least seven years.

\section{BIBLIOGRAPHY}

1. Houssay, B. A., Hypophysis and metabolism. New England J. Med., 1936, 214, 961.

2. Young, F. G., Permanent experimental diabetes produced by pituitary (anterior lobe) injections. Lancet, 1937, 2, 372.

3. Albright, F., Studies on ovarian dysfunction; menopause. Endocrinology, 1936, 20, 24.
4. Hoet, J. P., and Gessler, C., Pathologie van de schildklier. Vlaamsch Geneesk. Tijdschrift, 1937, 17, 281.

5. Barnes, B. O., Regan, J. F., and Nelson, W. O., Improvement in experimental diabetes following the administration of amniotin. J. A. M. A., 1933, 101, 926.

6. Nelson, W. O., and Overholser, M. D., Effect of oestrogenic hormone on experimental pancreatic diabetes in monkey. Endocrinology, 1936, 20, 473.

7. Rathery, F., and Rudolf, M., Folliculine, insuline et diabète. Bull. et mém. Soc. méd. d. hôp. de Paris, 1928, 52, 741.

8. Carnot, Terris, and Caroli, Un cas de "diabète ovarien," résistant à l'insuline, très amélioré par la folliculine. Bull. et mém. Soc. méd. d. hôp. de Paris, 1928, 52, 738.

9. Mazer, C., Meranze, D. R., and Israel, S. L., Evaluation of constitutional effects of large doses of estrogenic principle. J. A. M. A., 1935, 105, 257.

10. Jones, M. S., and MacGregor, T. N., Inhibitory effect of follicular hormone on anterior pituitary in humans. Lancet, 1936, 2, 974.

11. Collens, W. S., Slo-Bodkin, S. G., Rosenbliett, S., and Boas, L. C., Effect of estrogenic substance on human diabetes. J. A. M. A., 1936, 106, 678.

12. Glen, A., and Eaton, J. C., Insulin antagonism. Quart. J. Med., 1938, 7, 271.

13. De Wesselow, O. L. V., and Griffiths, W. J., On possible rôle of anterior pituitary in human diabetes. Lancet, 1936, 1, 991.

14. Himsworth, H. P., Diabetes mellitus; its differentiation into insulin-sensitive and insulin-insensitive types. Lancet, 1936, 1, 127.

15. Hall, F. C., Menopause arthralgia ; study of 71 women at artificial menopause. New England J. Med., 1938, 219, 1015.

16. Bjering, $T$., Investigation of diabetogenous hormone in urine. Acta med. Scandinav., 1938, 94, 483.

17. Young, F. G., Glycogen and metabolism of carbohydrate. Lancet, 1936, 2, 237 and 297.

18. Young, F. G., Experimental investigations on relationship of anterior hypophysis to diabetes mellitus. Proc. Roy. Soc. Med., 1938, 31, 1305.

19. Long, C. N. H., Disturbances of endocrine balance and their relation to diseases of metabolism. Ann. Int. Med., 1936, 9, 1619.

20. Elmer, A. W., Giedosz, B., and Scheps, M., Anterior pituitary and its diabetogenic and pancreatropic (blood sugar decreasing) activity. Acta med. Scandinav., 1937, 93, 487.

21. Neufeld, A. H., and Collip, J. B., Studies of effects of pituitary extracts on carbohydrate and fat metabolism. Endocrinology, 1938, 23, 735.

22. Taubenhaus, M., Untersuchungen über das Kohlehydrat- und Fettstoffwechsel-Hormon der Hypophyse bei Diabetikern und bei Hypophysentumoren. Wien. Arch. f. inn. Med., 1936, 29, 251. 